\title{
NUTRACEUTICALS AND HERBALS AS ADJUVANTS IN THE CHEMOTHERAPY OF CANCER? A REVIEW
}

\author{
JOHN MANI PHILIPS NATHALA ${ }^{1}$, SHIVASHREE ${ }^{1}$, SAHYADRI M ${ }^{1}$, MANJULA SN ${ }^{1 *}$, VIPAN K PARIHAR ${ }^{2}$ \\ ${ }^{1}$ Department of Pharmacology, JSS College of Pharmacy, JSS Academy of Higher Education and Research, Mysuru, Karnataka, India. \\ ${ }^{2}$ Department of Radiation Oncology, University of California, Irvine, California, USA. Email: snmanjula@jssuni.edu.in
}

Received: 10 December 2019, Revised and Accepted: 20 January 2020

\section{ABSTRACT}

Cancer is the third leading cause of death worldwide. The current cancer treatments such as chemotherapy and radiotherapy resulting in the development of unintended adverse effects that reduce the quality of life and economic burden in oncology patients. Nutraceuticals along with food value have natural bioactive components that have reassuring therapeutic properties in several diseases. Herbs of significant interest have been proven to prevent and treat various types of cancer and also reduce the side effects of chemotherapy and radiotherapy. The efficacy of nutraceuticals and herbs such as chemopreventive and chemotherapy is highlighted. We conclude that further studies are required to countersign the targeted approaches and efficacy of herbs and nutraceuticals in cancer patients as adjuvant therapy.

Keywords: Nutraceuticals, Herbals, Chemotherapy, Cancer, Adjuvant therapy.

\section{INTRODUCTION}

The world's third leading cause of death, especially in the middle-aged group inhabiting established realms. Compared to other fatal morbidity diseases, it is superior due to the revolution in routine, food customs, and treatment for significant disorders and diseases [1]. Such high death percentage climaxes the quandary of conventional chemotherapy and radiotherapy practiced in controlling this deadly disorder. These treatment regimens develop an increase in resistance, adding to the unadorned side effects of radiotherapy and chemotherapy; such treatment options additionally develop modern resistance of most cancerous cells toward the treatment [2].

Conversion of a normal cell into an invasive malignant phenotype necessitates tiers of initiation, development, and promotion through changing the unique genetic code. Although a single factor cannot reject the predisposition, people are at higher risk due to other additional factors, such as few high-risk cases, which may have a similar genetic context, nutritional, and dietary adoptions, which may determine the outcome of health [3].

Evolving revisions advocate that few plants originated intermediaries might influence molecular and cellular cascades of primary fundamental lump advance. However, some of these molecules may hurt traditional therapeutic standards. Numeral revisions by researchers steer onto herbals, anti-oxidants, unreal (synthetic) moieties to fix their corresponding characters in the supervision of countless forms of malignancy as adjuvants to chemotherapy and radiotherapy; meanwhile, assuming that they may advance the feat of malignancy treatment, though this view is debatable. Although this area is under exploration for over 40 years, even today there are still many qualms about their ultimate role.

\section{CANCER STAND IN INDIA}

"National Cancer Registry Program" is active since 1991 in reporting about the epidemiological subjects who are Indian inhabitants. The predictable cancer prevalence was a tad more in women. Certain types of cancer such as the esophageal, pharyngeal, stomach, lung, and oral cancers are more intricate in man, on the other hand, cervical and breast cancer stand at high incidence in females, followed by oral, gastric, and esophagus.
The intensifying figure of novel malignancy cases denotes the status of cancer exploration across India. The present research image ranges from basic studies required in governing the carcinogens to the research techniques to evaluate different molecular pathways and new drugs for treatment.

\section{MOST NOTED ANTICANCER TREATMENTS WITH ADVERSE EFFECTS}

The chemotherapeutic agents are well-recognized agents that are associated with severe adverse effects leading to the decreased quality of life and economic burden. In India, there are no extensive published data regarding the adverse effects of anticancer agents [4]. The cancer patients immensely suffered from adverse effects since chemotherapy regimens are highly complicated, and oncology patients are the inclined population with little tolerance [5]. The most common anticancer drugs causing adverse effects are imatinib, docetaxel, gemcitabine, paclitaxel, oxaliplatin, capecitabine, 5-fluorouracil, vincristine, 6-mercaptopurine, and gefitinib [6] which can cause cardiovascular toxicity, hepatotoxicity, neurotoxicity, nephrotoxicity gastrointestinal toxicity, and dermatological toxicity [7]. Radiation therapy can have specific or other side effects depending on which area of the body is being treated. Radiation to the brain can also have side effects that show up usually from 6 months to several years after treatment ends. Serious delayed effects can include memory loss, stroke-like symptoms, and poor brain function. Radiation to the breast can affect heart or lungs as well causing other side effects such as chemobrain, lymphedema, and some side effects of radiation therapy such as skin problems and fatigue can happen no matter at which part of the body is being treated [8].

\section{NUTRACEUTICALS}

Plentiful epidemiological, biological, and clinical revisions direct a stable connection among dietetic factors and lesser peril for developing malignancy. Dietary factors can prevent cancers, and they, on the other hand, can induce cancers [9]. The usual (natural) bioactive foods which deem to havee nutritional value and used in numerous ailments based on their beneficial effects are termed to be nutraceuticals. In trend cancer remedy approaches, which include chemotherapy and radiotherapy, induce unintended extra effects negotiating the lifetime of sufferers [10]. 
A massive sum of revisions has confirmed that dietary routine stands as one of the top vital determining factors of enduring diseases such as diabetes, cardiovascular disorder, neurodegenerative diseases, and different types of malignancy [11]. such connotations between disease and the dietary habit displays that nutrition has a straight effect on healthiness. The increasing desire for longevity, growing urbanization, subsequent environmental changes, and lifestyle has made cancer a steadily growing health problem globally. Therefore, many research papers and surveys show the influence of environmental surroundings and food regimen on the cellular function and health of an individual.

Some nutritional dietary supplements protect the body from most cancers through cleansing, even as others resource in lowering the noxious effects of radiotherapy and chemotherapy. The unfavorable side effects related to chemotherapy aggravate the dietary issues, and the right amount of nutrient supplement must be a critical part of chemotherapy. Nutraceuticals save you from the side effects of both with the aid of intervening or editing the biologic response [12].

The primary belief of nutraceuticals was well-thought-out as organic foods to deliver strength and was advised daily for consumption within the body for well-being until the year 1990. For instance, quite a lot of food industries initiated to augment iodine in the table salt to avoid goiter during the early $19^{\text {th }}$ century, which epitomizes the efforts on the way to making purposeful components [13].

In the new $21^{\text {st }}$ century, the earlier concept of nutraceuticals as effective therapeutic supplements and their enormous budding awareness is shown, leading to the recognized idea of nutraceutical medicine as a new branch of "complementary and alternative medicine". Around two millennia past, hippocrates, the father of western medicine, advised: "Let food be thy medicine and medicine be thy food" accentuating the affiliation among human health and nutrition, in actual it is among the precise vitamins for health and their healing paybacks. Plant food products can be defined as food supplements, functional foods, and nutraceuticals on the basis of the isolation step. Where unadulterated and purely extracted plant molecules are referred to as nutraceuticals, semi-purified plant products, which are not considered regular food, are referred to as functional food [14].

Foods that can be taken recurrently as a diet to uphold the overall health are termed to be food supplements. Plant food features many ingredients such as phytonutrients, polyunsaturated lipids, and secondary metabolites such as flavonoids, glucosinolates, lignans, phytosterols, polyphenols, phytoestrogens, phytates, and terpenes [15].

\section{CURRENT SCENARIO}

Since the ancient humankind, the extracts of herbals and natural materials are still under use for various purposes. At present, around 470 nutraceutical and functional food products are available with documented health benefits. In the process of pharmaceutical development, clinical test results from animal tests and studies to ascertain the effects are legally required; for now, there is no documentation strategy for foods used to prevent diseases in the ancient era.

Nutraceuticals used for cancer usually are as follows:

- Soyfoods are a source of isoflavones that possess cancer chemopreventive properties.

- Lycopene concentrates on the testes, skin, prostate, and adrenal protecting against cancer.

- Saponins possess antitumor and antimutagenic activity.

- Curcumin, a polyphenol of turmeric possess anticarcinogenic, antioxidative, and anti-inflammatory properties and so on.

- There have been reports of anti-tumor activity in vegetables and fruits such as beetroots, cucumber fruits, and spinach leaves.

Coming to India's nutraceutical scenario, poor eating habits and sedentary lifestyles have indeed led to an increase in the incidence of diet and health complications, although there is growing public awareness of the importance and value of proper nutrition and diet for good health and longevity.

It has been reported that many nutraceuticals are incredibly active and also have a profound effect on cell metabolism and sometimes have a little adverse effect. They have always been new and competed against India's underdeveloped pharmaceutical industries. The French oncologist reported that high doses of nutrients were used in conjunction with conventional chemotherapy in patients with lung cancer, which reduced the recurrence of the tumor to half, which also reduced cytotoxic levels [16].

\section{Vitamin C}

It reduced the formation of nitrosamine in the intestinal tract, which reduced the incidence of stomach and esophageal cancers significantly. The survival time of people treated for terminal cancers has increased. Epidemiological studies appear to point to ascorbate as a possible chemopreventive for breast cancer. A Latin American study compared nutrient intake and dietary patterns of 748 cervical cancer patients with 1411 controls [17]. The results supported a protective effect of Vitamin C against invasive cervical cancer. An inverse relationship between Vitamin C status and risk for cervical dysplasia was observed. The relationships of dietary and supplemental factors with esophageal cancer were examined in 147 males with esophageal cancer and 264 males with other diagnoses at Roswell Park Memorial Institute. Vitamins C, A, and intakes of fruits and vegetables were associated with decreased risks of esophageal cancer [18].

\section{Fish oil}

In hyperthermia and chemotherapy, eicosapentaenoic acid improved tumor inhibition by altering the cancer cell membranes, which increased vulnerability [19].

\section{Selenium}

A trace element is known for its antitumor genic effects. It is a powerful antioxidant found in enriched white rice, seafood, and whole wheat. Glutathione peroxidase, an antioxidant enzyme that protects against free radical damage, constitutes selenium. Increased risk of cancer is reported in the world's soil which is deficient in selenium resulting in low selenium intake. People need very little selenium to protect their health [20].

\section{Ginseng}

Panax ginseng improves the use of mitomycin (anticancer and antibiotic) to increase the anticancer drug's potency. Nutrition therapy enables medical therapy to make the most selective toxins (anticancer drugs) on the tumor cells [21].

\section{Avemar ${ }^{\mathrm{TM}}$}

Avemar is a formulated and "Approved dietary food for special medical purposes of cancer patients," it is fermented wheat gram extract that is highly recommended into adjuvant protocols (supported by the clinical study) of high-risk skin cancer patients [22]

\section{HERBALS}

Herbal drugs include plants, plant mix, and green complexes. In allopathic and traditional medicine, herbal plants were used across the ecosphere in a variety of ways. Herbal medicines are recognized for their efficacy, affordability, convenience, and safety. Regardless of advancements in synthetic chemistry, approximately $80 \%$ of the ecosphere's inhabitants still hang onto medicinal plants for the treatment of disease [23]. The biological activity of any plant is due to its components, i.e., phytochemicals, flavonoids, and phenols. They are plant-based constituents that directly arbitrate their positive health benefits by changing precise molecular objectives directly or indirectly as stabilized conjugates affecting metabolic cascades [24]. Natural anticancer products offer valuable means of increasing cancer treatment to a new level of success with less or no adverse side effects [25]. The 
precise use of phytochemicals in this era of medicines may provide us with new dimensions in improving the outcome of chemotherapy. For the past 30 years, natural products, especially those from the plant kingdom, have been a vital source of chemotherapy [26]. "Cancer is hostile to the human body, and hostile environment is cancerous to plants" which means that the plants which can proliferate in multiple but diverse environments may naturally provide us with a vital source of anticancer agents [27].

Herbs are usually classified according to their behavior, herbs alter the immune system and chemoprotective herbs. Herbs that modify the immune system show a significant increase in cancer patient's resistance [28]. Malignant cells subsequently decline the immune system's potency by truncated immunogenicity in people with cancer. Most herbal medicines stimulate immunity and improve it [29] and also protect the bone marrow against chemotherapy's myelosuppressive side effects. Herbal medicines prevent the progression of oncogenic apoptosis. Instance, the apoptosis in cancer cells is bought by curcumin, which blocks the NF-KB signaling pathway through the regulatory phosphorylation of the IKB enzyme [30].

\section{HEALTH BENEFITS OF DIFFERENT HERBS AND HERBALS DURING CANCER}

\section{Ellagic acid}

Ellagic acid is a polyphenol compound extant in many nuts, seeds, and fruits, such as black raspberries, pomegranates, walnuts, strawberries, raspberries, and almonds. In another study, Baradaran et al. showed that ellagic acid has a chemoprotective effect due to strong antioxidant properties, which lead to reducing OS [31]. Some studies in the past also indicated that ellagic acid showed chemoprotective, anti-apoptotic, and anticarcinogenic properties that make it interesting for further studies in different disorders particularly cancer cell systems [32].

\section{Vinca rosea (periwinkle)}

Periwinkle, also called Catharanthus roseus, is the foremost antitumor herb. The components of this are vinca alkaloids such as vincristine (leurocristine), vinblastine, and reserpine. To display their anticancer property, it is essential for the alkaloids to bind with tubulin (microtubule protein), resulting in the halt of microtubules and constraint in the construction of spindles during the metaphase hence, halt the division of malignant cells [33]. Vinblastine is used in treating Hodgkin's disease, a malignancy of kidney, and nonHodgkin's lymphoma. Nevertheless, vincristine is prescribed with a combination of other anticancer agents for the effective treatment of various cancers such as lung, breast, cervix, and liver [34]. As of now, periwinkle's herbal compounds were legalized by the FDA for treating the neoplasm. In general, vincristine has used the drug during breast cancer [33].

\section{Limitations}

It has aftereffects like a loss of the need to eat, bone ache, unhappiness, giddiness, constipation, intestinal pain, and hair loss [35]

\section{Curcuma longa (turmeric)}

Curcuma Longa confirms the full gamut of therapeutic effects. It is antitumor, anti-inflammatory,-antioxidant, antimutagenic, antifungal, antiviral, antibacterial, and hepatoprotective. Constituted curcumin averts the making of eicosanoid (injurious) like PGE-2, henceforth, hinders the cancer cell's progress [36]. Curcuminoids extracted from turmeric like curcumin (Di-feruloyl-methane) suppressed cancer cells at each step, i.e., initiation, growth, and metastasis by hindering the malignant cell propagation in $\mathrm{G}_{2} / \mathrm{S}$ phase and inducing apoptosis. It also hinders angiogenesis, a rate-limiting step in the metastasis and growth of malignancy [37]

\section{Limitations}

$1 \mathrm{~g} /$ day ingestion of turmeric till 9 months exerted substantial effects on the worsening of precancerous lesion of palatal malignancies. Although, after administering turmeric powder of dose up to $10 \mathrm{~g} / \mathrm{kg}$, no acute toxic signs are observed [38]

\section{Nigella sativa (Kalonji or black cumin)}

Known as Kalonji in South Asia used to promote health and fight diseases. By tradition, it is used in the promotion of overall health conditions besides during a headache, cold, and microbial infections [39] and it also stimulates the immune system by increasing helper T cells (T4) to suppressor T cells (T8) ratio and literature also states that is also refined the natural killer cell activity by decreasing the immune globulin (IgA, IgM, and also IgG) levels [40].

\section{Anticancer activity}

$N$. sativa is immune-modulating, immune-potentiating, and acts like interferon. Ethanolic extract of $N$. sativa was found to inhibit cancer cell progression of endothelial cells in vitro [41]. Thymoquinone and di-thymoquinone, active constituents of $N$. sativa were found to have potent anticancer activity at odds with various cancers they have shown their strong cytotoxic actions even on the multidrug resilient humanoid tumors which were 10 -fold more resistant to etoposide and doxorubicin [39]. MCF-7 breast cancer cell line in vitro was inactivated after the treatment with alcoholic extract or in combination with hydrogen peroxide. $N$. sativa terminates malignant cells by attaching

Table 1: Health benefits of certain nutraceuticals and herbals during cancer treatment

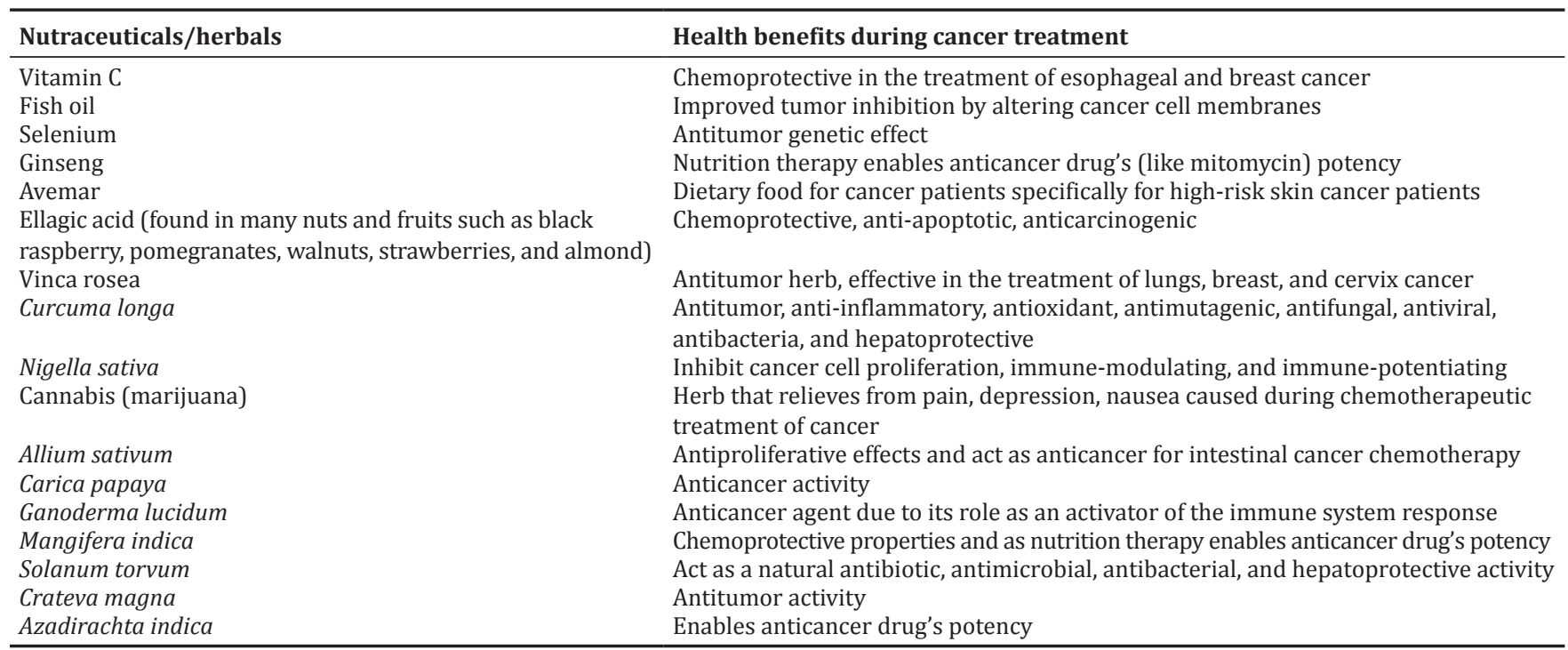


to the asialofetuin (lectin) superficially, instigating their clumping and aggregation [42].

\section{Limitations of $N$. sativa}

Acutely toxic once administered $25 \mathrm{~g} / \mathrm{kg}$ orally. However, noxious indications appear once administered $25 \mathrm{~g} / \mathrm{kg}$ intravenously [43]

\section{Cannabis (marijuana)}

Cannabis sativa is a magic herbal that relieves from pain, depression, and nausea caused during chemotherapeutic treatment of cancer " $\triangle$ 9-tetrahydrocannabinol (THC)" is the core integral moiety found in cannabis that is accountable for its pharmacological activity in the curative medicinal ground [44-47]. Researchers sign post the upsurge of weight gain and appetite after the ingestion of marijuana (cannabis) for AIDS-associated anorexia and cancer patients [45]. "Nabilone (Cesamet)," a synthetic derivative of THC, was active in governing chemotherapy brought vomiting and nausea [46]. Moreover, it is also effective in treating the children undergoing chemotherapy [47].

\section{Limitations of cannabis}

Although the side effects of cannabis are not every so often understood in the bodily facets, cognitive, or mental domain, like powerlessness to recognize the time interval and distant objects and memory thought manners [48].

\section{Allium sativum (garlic)}

The beneficial use of A. sativum for the treatment of cancer was first endorsed by the father of western medicine, i.e., Hippocrates. It has defensive possibilities and partakes in enhancing the immune system [49]. "Allicin, S-allyl cysteine, di-allyl-di-sulfide, and di-allyl-trisulfide cristine" possess anticancer activity. It plays an important role in intestinal cancer chemotherapy. Metabolic by-products of organicsulfur constituents of garlic are responsible for its antiproliferative effects [50].

\section{Carica papaya}

C. papaya (fruitless type) extract inhibited the cell growth when tested against the MCF-7 cell line at different concentrations $(25,50,100,200$ and $400 \mu \mathrm{g} / \mathrm{ml}$ ). It exhibited exponential growth in inhibiting the cell growth on increasing the concentrations, the lowest growth inhibition being $9.38 \%$ at $25 \mu \mathrm{g} / \mathrm{ml}$, and the highest growth inhibition was $71.76 \%$ at $400 \mu \mathrm{g} / \mathrm{ml}$. The IC $\mathrm{I}_{50}$ value was more than $233.01 \mu \mathrm{g} / \mathrm{ml}$. This study reveals that $C$. papaya extract possesses anticancer activity[51]

\section{Ganoderma lucidum}

It has been a substantial source of natural mycological remedies for many years. Nevertheless, the usage of Ganoderma is poorly depicted in the field of cancer immunotherapy. Ganoderma's betaglucan polysaccharide plays a significant role in immune surveillance and chemoprevention of cancer [52]. The most comprehensively investigated important pathways are NF-kB and MAPK. The broadspectrum application of Ganoderma enables us to use it for the treatment of cancer and immune disorders and as an adjunct to modern cancer therapies due to its is regulatory actions of the immune system [53]. Available evidence suggests that the efficacy of Ganoderma species as an anticancer agent due to its role as an activator of the immune system responses. Much literature is available about the other natural sources such as microorganisms and marine, which can be used as chemotherapeutic agents directly or indirectly [54].

\section{Mangifera indica (Mango)}

Mango pulp extract (MPE) and lupeol were evaluated for chemopreventive properties against 7, 12-dimethylbenz (a) anthracene induced alteration in the liver of Swiss albino mice. MPE was found to be effective in combating cellular injury of mouse liver by modulating cell-growth regulators which were induced through oxidative stress [55]. Prasad et al. reported that mangiferin increased the efficacy of doxorubicin in MCF-7 [56].

\section{Solanum torvum Sw. (night berries)}

Solanum torvum Sw. is a member of the family Solanaceae, and its fruits are commonly called night berries which are useful for treating liver and spleen enlargement, cough and also used as a hematopoietic, antimicrobial, and analgesic agent. The leaf extract has been reported to have antiviral and antiulcerogenic properties. The fruit coat exhibited significant antibacterial activity against pathogenic bacteria when compared to standard antibiotics and hence acted as a natural antibiotic. Recently, it has been reported that this fruit extract has hepatoprotective activity [57,58]; therefore, apparently this fruit extract can be used as adjuvant therapy for chemotherapy-induced hepatotoxicity

\section{Crateva magna}

C. magna belongs to the family Capparaceae commonly used in the treatment of urinary disorders. Currently, in vivo and in vitro antitumor activity of leaves C. magna has been reported [59]. This study reveals that the ethanolic extract of $C$. magna has antitumor activity [60].

\section{Azadirachta indica (neem)}

Studies of extracts from all major parts of neem plant, including leaves, flowers, fruits, and seeds, have shown promising chemopreventive and therapeutic effects in pre-clinical research [61]. The underlying mechanisms of such anticancer effects of neem have begun to unravel with accumulating studies. As a natural resource, neem extract has the advantages of easy availability, low cost, and safety to humans, which collectively make neem-derived compounds valuable candidates for anticancer therapy [62]. Preclinical studies have primarily established neem as a potential preventive and therapeutic agent against various types of cancer [63].

Interestingly, neem has been shown to improve the efficacy of other anticancer drugs besides its anticancer functions as a single agent [64-66]. The combination of neem-derived gedunin and cisplatin further decreases the proliferation of treated ovarian cancer cells by almost $50 \%$ compared to the cells treated with only cisplatin [61]. The combination of a sub-lethal dose of ethanolic NLE and cisplatin also provides synergistic effects in decreasing the viability of breast and cervical cancer cells compared to individual compounds alone $[67,68]$. Further investigation is warranted to determine whether neem could sensitize cancer cells to the cytotoxic effects of other therapeutic regimens and whether combination therapy could offer potential clinical benefits.

\section{ADJUVANT THERAPY - HOW IMPORTANT IS IT?}

All the therapies to fight cancer are advanced into the age of specific molecular targets, yet the current therapies are inadequate because of the severe side effects of antitumorigenic agents and cell-signaling complexity. It is evident that a few types of cancers are resistant to conventional chemotherapeutic agents. Desired results with the least number of side effects have been obtained with adjuvant therapies that have also improved the quality of life. Although, it is associated with dose-relationships. Therefore, it is necessary for mechanistic and targeted approaches for improving the quality, efficacy, and minimizing unwanted effects, which is crucial during the chemotherapeutic treatment. Although, shortlisting the appropriate adjuvant will always be the rate-limiting step to achieve effective adjuvant synergism.

Over the past few years, many nutraceuticals and few dietary agents are deemed to imitate the actions of anticancer drugs, which can be used as adjuvants during chemotherapy refer Table 1 . Few agents act through regulation of various cell signaling pathways which in turn changes the fate of biological systems. For the fact, many of such agents were proven to be nontoxic and synergistic when used along with the different classes of anticancer drugs. Therefore, it is evident that these agents can be combined with anticancer drugs which could be of profitable use in dealing with cancer and its side effects. 


\section{CONCLUSION}

The use of herbs and nutraceuticals is growing rapidly every day but the molecular and mechanistic actions of respective classes from natural sources are still lacking profound clinical data. Therefore, there is a need for practices like adjuvant therapy in addition to conventional chemotherapy. Adjuvant therapy not only renders the effectiveness of conventional chemotherapy but also increases the quality of life of patients, for which awareness should be created among the public regarding the promising use of certain herbs and nutraceuticals as an adjuvant which might be helpful in the critical need of the hour

\section{AUTHORS' CONTRIBUTIONS}

All authors have equally contributed to reviewing the preparation and editing of the manuscript.

\section{CONFLICTS OF INTEREST}

We declare that there are no conflicts of interest.

\section{REFERENCES}

1. Cancer. Available from: https://www.who.int/news-room/fact-sheets/ detail/cancer

2. Weller D, Vedsted P, Rubin G, Walter FM, Emery J, Scott S, et al. The Aarhus statement: Improving design and reporting of studies on early cancer diagnosis. Br J Cancer 2012;106:1262-7.

3. Cancer and Aging the Inflammatory Connection. Available from: http:// www.aginganddisease.org/article/2017/2152-5250/ad-8-5-611.html.

4. Kirthi C, Afzal A, Reddy M, Aamir Ali S, Yerramilli A, Sharma S A study on the adverse effects of anticancer drugs in an oncology center of a tertiary care hospital. Int J Pharm Pharm Sci 2014;6:580-3.

5. Sunny S. Assessment of adverse effects of most commonly prescribed anticancer drugs in a tertiary care teaching hospital. Indian J Pharm Pract 2017; 10:270-5

6. Chopra D, Rehan HS, Sharma V, Mishra R. Chemotherapy-induced adverse drug reactions in oncology patients: A prospective observational survey. Indian J Med Paediatr Oncol 2016;37:42-6.

7. Baldo P, Fornasier G, Ciolfi L, Sartor I, Francescon S. Pharmacovigilance in oncology. Int J Clin Pharm 2018;40:832-41.

8. How Radiation Therapy Can Affect Different Parts of the Body Available from: https://www.cancer.org/treatment/treatments-and-sideeffects/treatment-types/radiation/effects-on-different-parts-of-body. html.

9. Baena Ruiz R, Salinas Hernández P. Diet and cancer: Risk factors and epidemiological evidence. Maturitas 2014;77:202-8.

10. Wargovich MJ, Morris J, Brown V, Ellis J, Logothetis B. Nutraceutical use in late-stage cancer. Cancer Metastasis Rev 2012;29:503-10.

11. Willett WC, Koplan JP, Nugent R, Dusenbury C, Puska P, Gaziano TA. Prevention of chronic disease by means of diet and lifestyle changes. In Jamison DT, Breman JG, Measham AR, Alleyne G, Claeson M, Evans DB, Jha P, editors. Disease Control Priorities in Developing Countries $2^{\text {nd }}$ ed. Washington, DC: World Bank; 2006.

12. Lobo V, Patil A, Phatak A, Chandra N. Free radicals, antioxidants and functional foods: Impact on human health. Pharmacogn Rev 2010;4:118-26

13. Santini A, Novellino E. To nutraceuticals and back: Rethinking a concept. Foods 2017;6:e74

14. Varzakas T, Zakynthinos G, Verpoort F. Plant food residues as a source of nutraceuticals and functional foods. Foods 2016;5:88.

15. Kitts D. Bioactive substances in food: Identification and potential uses. Can J Physiol Pharmacol 1994;72:423-34.

16. Arruebo M, Vilaboa N, Sáez-Gutierrez B, Lambea J, Tres A, Valladares $\mathrm{M}$, et al. Assessment of the evolution of cancer treatment therapies. Cancers (Basel) 2011;3:3279-330.

17. Herrero R, Potischman N, Brinton LA, Reeves WC, Brenes MM, Tenorio $\mathrm{F}$, et al. A case-control study of nutrient status and invasive cervical cancer. I. Dietary indicators. Am J Epidemiol 1991;134:1335-46.

18. National Research Council (US) Committee on Nutrition, and Cancer $17^{\text {th }}$ Relationship of Diet to Cancer at Specific Sites. United States: National Academies Press; 1982.

19. Chemo and Radiation. Nutrition and Cancer. Available from: https:// www nutritioncancer.com.

20. Tapiero H, Townsend DM, Tew KD. The antioxidant role of selenium and seleno-compounds. Biomed Pharmacother 2003;57:134-44.
21. Chen S, Wang Z, Huang Y, O'Barr SA, Wong RA, Yeung S, et al. Ginseng and anticancer drug combination to improve cancer chemotherapy: A critical review. Evid-Based Complement Altern Med 2014;2014:168940

22. Demidov LV, Manziuk LV, Kharkevitch GY, Pirogova NA, Artamonova EV. Adjuvant fermented wheat germ extract (Avemar) nutraceutical improves survival of high-risk skin melanoma patients: A randomized, pilot, phase II clinical study with a 7-year follow-up. Cancer Biother Radiopharm 2008;23:477-82.

23. Jain R, Rao B. Critical analysis of India's national mission on medicinal plants (NMMP) in providing access to quality botanical drugs to improve public health. J Ayurveda Integr Med 2015;6:198-207.

24. Tungmunnithum D, Thongboonyou A, Pholboon A, Yangsabai A. Flavonoids and other phenolic compounds from medicinal plants for pharmaceutical and medical aspects: An overview. Medicines 2018;5:e93.

25. Al-Snafi AE. Chemical constituents and pharmacological activities of Lantana camara a review. Asian J Pharm Clin Res 2019;12:10-20.

26. Demain AL, Vaishnav P. Natural products for cancer chemotherapy Microb Biotechnol 2011;4:687-99.

27. Greenwell M, Rahman PK. Medicinal plants: Their use in anticancer treatment. Int J Pharm Sci Res 2015;6:4103-12.

28. Lichota A, Gwozdzinski K. Anticancer activity of natural compounds from plant and marine environment. Int J Mol Sci 2018;19:3533.

29. Yin SY, Wei WC, Jian FY, Yang NS. Therapeutic applications of herbal medicines for cancer patients. Evid Based Complement Altern Med 2013;2013:302426

30. Albulescu M. Phytochemicals in Antitumor Herbs and Herba Formulas. Phytochemicals Isolation, Characterisation and Role in Human Health; 2015. Available from: http://www.intechopen.com/ books/phytochemicals-isolation-characterisation-and-role-in-humanhealth/phytochemicals-in-antitumor-herbs-and-herbal-formulas. [Last accessed on 2020 Jan 14].

31. Safarzadeh E, Shotorbani SS, Baradaran B. Herbal medicine as inducers of apoptosis in cancer treatment. Adv Pharm Bull 2014;4 Suppl 1:421-7.

32. Ismail T, Calcabrini C, Diaz AR, Fimognari C, Turrini E, Catanzaro E, et al. Ellagitannins in cancer chemoprevention and therapy. Toxins 2016;8:151.

33. Sharma P, McClees SF, Afaq F. Pomegranate for prevention and treatment of cancer: An update. Mol J Synth Chem Nat Prod Chem 2017;22:177.

34. Moudi M, Go R, Yien CY, Mohd N. Vinca Alkaloids. Int J Prev Med 2013;4:1231-5

35. Quintão NL, Santin JR, Stoeberl LC, Corrêa TP, Melato J, Costa R. Pharmacological treatment of chemotherapy-induced neuropathic pain PPAR $\gamma$ agonists as a promising tool. Front Neurosci 2019;13:907.

36. Periwinkle: A Herbal Powerhouse, Side Effects and Dosage, HealthXP. Available from: https://www.healthxp.in/periwinkle-a-herbal-powerhouseside-effects-dosage. [Last accessed on 2020 Jan 14].

37. Ruby AJ, Kuttan G, Babu KD, Rajasekharan KN, Kuttan R. Antitumour and antioxidant activity of natural curcuminoids. Cancer Lett 1995;94:79-83

38. Klinger NV, Mittal S. Therapeutic potential of curcumin for the treatment of brain tumors. Oxid Med Cell Longev 2016;2016;9324085.

39. Park W, Amin AR, Chen ZG, Shin DM. New perspectives of curcumin in cancer prevention. Cancer Prev Res (Phila) 2013;6:387-400.

40. Khan MA, Chen HC, Tania M, Zhang DZ. Anticancer activities of Nigella sativa (black cumin). Afr J Tradit Complement Altern Med 2011;8:226-32.

41. Yimer EM, Tuem KB, Karim A, Ur-Rehman N, Anwar F. Nigella sativa $\mathrm{L}$. (Black cumin): A promising natural remedy for wide range of illnesses. Evid Based Complement Altern Med 20192019:1528635.

42. Majdalawieh AF, Fayyad MW. Recent advances on the anti-cancer properties of Nigella sativa, a widely used food additive. J Ayurveda Integr Med 2016;7:173-80.

43. Salim EI. Cancer chemopreventive potential of volatile oil from black cumin seeds, Nigella sativa L., in a rat multi-organ carcinogenesis bioassay. Oncol Lett 2010;1:913-24

44. Zaoui A, Cherrah Y, Mahassini N, Alaoui K, Amarouch H, Hassar M. Acute and chronic toxicity of Nigella sativa fixed oil. Phytomedicine 2002;9:69-74.

45. Pellati F, Borgonetti V, Brighenti V, Biagi M, Benvenuti S, Corsi L. Cannabis sativa L. and nonpsychoactive cannabinoids: Their chemistry and role against oxidative stress, inflammation, and cancer. BioMed Res Int 2018;2018:1691428.

46. Parker LA, Rock EM, Limebeer CL. Regulation of nausea and vomiting by cannabinoids. Br J Pharmacol 2011;163:1411-22. 
47. Dariš B, Tancer Verboten M, Knez Ž, Ferk P. Cannabinoids in cancer treatment: Therapeutic potential and legislation. Bosn J Basic Med Sci 2019;19:14-23.

48. Tapley P, Kellett S. Cannabis-based medicines and the perioperative physician. Perioper Med (Lond) 2019;8:19.

49. Tariq AL, Reyaz AL. Isolation of cannabinoids from the plant Cannabis sativa and its potential anticancer activity. Int $\mathrm{J}$ Drug Dev Res 2012;4:241-6

50. Lamm DL, Riggs DR. The potential application of Allium sativum (garlic) for the treatment of bladder cancer. Urol Clin North Am 2000;27:157-62, 11 .

51. Ariga T, Seki T. Antithrombotic and anticancer effects of garlic-derived sulfur compounds: A review. Biofactors 2006;26:93-103.

52. Banu KS, Cathrine DL, Britto DJ. In vitro Anticancer Activity of Carica papaya. $6^{\text {th }}$ International Conference on Emerging Trends in Engineering, Technology, Science and Management; 2017.

53. Yuen JW, Gohel MD. Anticancer effects of Ganoderma lucidum A review of scientific evidence. Nutr Cancer 2005;53:11-7.

54. Sohretoglu D, Huang S. Ganoderma lucidum polysaccharides as an anti-cancer agent. Anticancer Agents Med Chem 2018;18:667-74.

55. Harhaji Trajković LM, Mijatović SA, Maksimović-Ivanić DD, Stojanović ID, Momcilović MB, Tufegdzić SJ, et al. Anticancer properties of Ganoderma lucidum methanol extracts in vitro and in vivo. Nutr Cancer 2009;61:696-707.

56. Prasad S, Kalra N, Shukla Y. Hepatoprotective effects of lupeol and mango pulp extract of carcinogen induced alteration in Swiss albino mice. Mol Nutr Food Res 2007;51:352-9.

57. Imran M, Arshad MS, Butt MS, Kwon JH, Arshad MU, Sultan MT. Mangiferin: A natural miracle bioactive compound against lifestyle related disorders. Lipids Health Dis 2017; 16:84.

58. Mohan M, Kamble S, Satyanarayana J, Nageshwar M, Reddy N Protective effect of Solanum torvum on doxorubicin induced hepatotoxicity in rats. 2011;3:131-8

59. Panigrahi S, Sundaram MM, Natesan R, Pemiah B. Anticancer activity of ethanolic extract of Solanum torvum SW. Int J Pharm Pharm Sci 2014;6:93-8

60. Meera R, Chidambaranathan N. Anti cancer activity of ethanolic extract of Crateva magna Lour (DC) against Ehrlich ascitic carcinoma cell lines in mice. J Pharm Sci 2017;9:5.

61. Deep A, Mruthunjaya K, Manjula SN. Antitumor activity of Crateva magna in transplantable tumor models in mice. Asian J Pharm Clin Res 2019;12:233-40.

62. Moga MA, Bălan A, Anastasiu CV, Dimienescu OG, Neculoiu CD, Gavriș C. An overview on the anticancer activity of Azadirachta indica (Neem) in gynecological cancers. Int J Mol Sci 2018;19:3898.

63. Hao F, Kumar S, Yadav N, Chandra D. Neem components as potential agents for cancer prevention and treatment. Biochim Biophys Acta 2014;1846:247-57.

64. Alzohairy MA. Therapeutics Role of Azadirachta indica (Neem) and their active constituents in diseases prevention and treatment. Evid Based Complement Alternat Med 2016;2016:7382506.

65. Gupta SC, Prasad S, Reuter S, Kannappan R, Yadav VR, Ravindran J, et al. Modification of cysteine 179 of IkappaBalpha kinase by nimbolide leads to down-regulation of NF-kappaB-regulated cell survival and proliferative proteins and sensitization of tumor cells to chemotherapeutic agents. J Biol Chem 2010;285:35406-17.

66. Gupta SC, Reuter S, Phromnoi K, Park B, Hema PS, Nair M, et al. Nimbolide sensitizes human colon cancer cells to TRAIL through reactive oxygen species- and ERK-dependent up-regulation of death receptors, p53, and Bax. J Biol Chem 2011;286:1134-46.

67. Bodduluru LN, Kasala ER, Thota N, Barua CC, Sistla R Chemopreventive and therapeutic effects of nimbolide in cancer: The underlying mechanisms. Toxicol In vitro 2014;28:1026-35.

68. Sharma C, Vas AJ, Goala P, Gheewala TM, Rizvi TA, Hussain A. Ethanolic neem (Azadirachta indica) leaf extract prevents growth of MCF-7 and HeLa cells and potentiates the therapeutic index of cisplatin. J Oncol 2014;2014:321754. 